\title{
Evaluating Diet and Sleep Quality of Shift and Non-Shift Nurses Using Three-Factor Pittsburgh Sleep Quality Index and Healthy Eating Index-2015
}

\author{
Gizem Helvaci, MSc ${ }^{1}$, Nazlı Nur Aslan Çin, $\mathrm{MSc}^{1}$, Şahinde Canbulat, $\mathrm{MSc}^{2}$, Hülya Yardimci, $\mathrm{PhD}^{1}$ \\ 'Department of Nutrition and Dietetics, Faculty of Health Sciences, Ankara University, Ankara, Turkey \\ ${ }^{2}$ Department of Nursing, Faculty of Nursing, Ankara University, Ankara, Turkey
}

Received: August 25, 2020

Revised: November 9, 2020

Accepted: December 1, 2020

Correspondence

Gizem Helvaci, MSc

Department of Nutrition and Dietetics,

Faculty of Health Sciences, Ankara University,

Fatih Street. No:197, A Keçiören,

Ankara 06290, Turkey

Tel $+90(312) 3812350-6567$

Fax +90(312)3812355

E-mail ghelvaci@ankara.edu.tr

ORCID

Gizem Helvacı

https://orcid.org/0000-0001-8654-9245

Nazlı Nur Aslan Çin

https://orcid.org/0000-0002-4458-8817

Sahinde Canbulat

https://orcid.org/0000-0003-4264-9740

Hülya Yardımcı

https://orcid.org/0000-0002-2664-4176

( This is an Open Access article distributed under the terms of the Creative Commons Attribution Non-Commercial License (https://creativecommons.org/licenses/by-nc/4.0) which permits unrestricted non-commercial use, distribution, and reproduction in any medium, provided the original work is properly cited.
Background and Objective The objective of this study was to determine whether there were differences in diet and sleep quality between shift and non-shift nurses. Nurses among healthcare professionals mostly work in shifts. Therefore, they may face many health problems. Changes of their dietary pattern and sleep quality might be among underlying causes for their health risks.

Methods This descriptive and cross-sectional research enrolled 298 nurses working in two hospitals who volunteered to participate in this study. The work schedule of nurses included a non-shift work and a shift-work. Sleep quality was measured with the Pittsburgh Sleep Quality Index (PSQI). Data were analyzed using a three-factor PSQI model.

Results Based on the three-factor PSQI model, scores for sleep efficiency, sleep quality, and daily disturbances were significantly $(\mathrm{p}<0.05)$ higher in shift nurses than in non-shift nurses. Among individuals with good sleep quality, the diet quality of shift nurses was worse $(\mathrm{p}<0.05)$ than that of non-shift nurses. Among individuals with poor sleep quality, there was no significant ( $p>0.05$ ) difference in total diet quality score according to shift status.

Conclusions Shift work was significantly associated with poor sleep quality. Among nurses with good sleep quality, the diet quality of shift nurses was worse than that of non-shift nurses.

Sleep Med Res 2020;11(2):94-101

Key Words Diet, Nurses, Shift, Sleep.

\section{INTRODUCTION}

Nurses are obliged to provide 24-hour patient care, making shift work system obligatory [1]. Sleep problems are common among nurses working in shifts. Such sleep problems not only affects the health of nurses negatively, but also can lead to increased professional errors and decreased job satisfaction [2,3]. The alignment among sleep, nutrition, and physical activity constitutes the circadian rhythm. The shift work system disrupts the circadian rhythm. It may adversely affect glucose-insulin metabolism, substrate oxidation, leptin and ghrelin concentrations, hypothalamus-pituitary-adrenal axis activity, food reward, and appetite [4]. Therefore, it may increase the risk of gaining weight and developing metabolic dysfunction [5]. Obesity, gastrointestinal system diseases, cardiovascular system diseases, and type 2 diabetes are common health problems in shift workers [6].

The shift work system and intense workflow also have negative effects on eating behaviors and sleeping patterns of nurses. Although food choices of nurses depend on their own individual preferences, it is difficult to preclude unhealthy eating practices due to their working environment where unhealthy foods are always easily accessible whereas accessibility to healthy foods is generally limited. In addition, nurses' responsibility to immediately respond to all needs 
of patients minimizes their individual control over eating habits [7]. To keep themselves awake, nurses who are on duty at night show abnormal eating behaviors. They may consume more sweets and snacks [8]. A trend toward consuming more fatty foods at breakfast after a night shift has been reported [9]. These changes in eating patterns of shift workers are associated with increases of body mass index (BMI) [10].

Shift work system, sleep quality, and eating behavior are important determinants of nursing service efficiency. For nurses to provide better care with fewer resources, it is important to identify these determinants and take precautions against them [11]. Therefore, the first objective of this study was to determine whether there were differences in diet quality and sleep quality between shift and non-shift nurses. The second objective of this study was to determine the relationship between three-factor sleep quality and shift work adjusted by potential confounding factors.

\section{METHODS}

\section{Study Design}

This was a cross-sectional study evaluating relationships among shift work, sleep quality, and diet quality of nurses. A total of 298 shift and non-shift nurses from two hospitals in Ankara, Turkey between September 15, 2017 and June 15, 2018 volunteered to participate in this study. Power analysis was conducted to determine the number of nurses needed to be included in this study. Error margin, power, and effect size were set at 0.05, 0.95, and 0.5 , respectively. It was found that at least 176 nurses would be needed to participate in this study. However, 298 nurses were enrolled to obtain more accurate results. All nurses from the two hospitals in Ankara were targeted to participate in this study. After excluding those who were on leave and those who refused to participate in this study, a total of 298 nurses were enrolled. The work schedule of nurses included a non-shift work (regular work) and a shift-work (rotating shift or a fixed night shift). This study was performed following ethical principles of the Helsinki. Informed consent was obtained from each individual who agreed to participate in this study. Approval of the Ethics Committee was received from Ankara University (56786525050.04.04/12403).

\section{Participants and Data Collection}

Turkish nurses aged between 19 years and 64 years were eligible to participate in this study. Inclusion criteria were: no history of diabetes or hypertension, no use of glucose or lipid metabolism drugs, not working at night on consecutive days, and currently working a hospital in Ankara. Pregnant or lactating women, known cases of diabetes, those with a history of any chronic illness, and those who were taking any medication that could affect glucose or lipid metabolism were excluded from this study.
Research data were collected using survey forms and face-toface interviews. The questionnaire consisted of questions about socio-demographic characteristics, anthropometric measurements, the Pittsburg Sleep Quality Index (PSQI), and 24-hour dietary recall (24HR). Before conducting the survey, each participant was informed about contents of this research and asked to sign an informed consent form indicating that he/she voluntarily agreed to participate in this study.

\section{Anthropometric measurements}

Weight $(\mathrm{kg})$ and height $(\mathrm{cm})$ of each participant were measured with a portable digital weighing machine and a rigid tape measure, respectively. BMI [body weight $(\mathrm{kg}) / \mathrm{height}\left(\mathrm{m}^{2}\right)$ ] was calculated based on body weight and height measurements. BMI values were evaluated according to the criteria of the World Health Organization [12].

\section{PSQI}

The PSQI was developed in 1989 by Buysse et al. [13].Validity and reliability of its Turkish version have been reported by Ağargün et al. [14], with Cronbach's alpha value of 0.80 . The scale was developed in order to evaluate individual sleep quality in the last month. It encompasses a total of 19 questions. Subjective sleep quality had seven sub-dimensions, including sleep latency, sleep duration, habitual sleep efficacy, sleep disturbance, use of sleeping pills, and daytime sleep dysfunction. The sum of points for sub-dimensions gave the total score which varied from 0 to 21. A score greater than 5 reflected a poor sleep quality, while a score equal to or less than 5 reflected a good sleep quality [13]. Sleep quality was further analyzed based on the "three-factor PSQI model" proposed by Cole et al. [15]. The sleep quality scale was divided into three factors according to confirmatory factor analysis. These factors were: factor 1 , sleep efficiency (sleep duration and sleep efficiency components); factor 2, sleep quality (subjective sleep quality, sleep latency and sleep medication use components); and factor 3, daily disturbances (sleep disturbances and daytime dysfunction components).

\section{One-Day 24-Hour Recall Method and Healthy Eating Index-2015}

One-day food intake of each participant was obtained with a $24 \mathrm{HR}$ method. All foods that nurses consumed for 24 hours the previous day were questioned and recorded by researchers. During recording, a photo catalogue of foods and nutrients was utilized for measures and amounts. "Photo Catalog of Foods and Nutrients: Measures and Amounts" was used in determining portion sizes of consumed foods [16]. Amounts of nutrients in foods that participants consumed outside or did not know their ingredients were estimated. Amounts of nutrients per portion were determined with the help of 'standard recipes' [17]. Average energy and nutritional facts of consumed foods were determined using the Nutritional Information Systems Package Pro- 
gram [18].

The healthy eating index-2015 (HEI-2015) score was calculated based on data derived from the $24 \mathrm{HR}$. HEI-2015 was composed of a total of 13 components, with nine determining dietary adequacy and four determining limited consumption. The sum of points for each component gave the total score (full score of 100 points), with higher score indicating better diet quality [19].

\section{Statistical Analysis}

Research data were evaluated and statistical analyses were performed using SPSS 21.0 program (IBM Corp., Armonk, NY, USA). A $\chi^{2}$ test was used to compare BMI and working year with shift work status. Fisher's exact test was used to compare sex, marital status, having children, smoking, alcohol use, and regular exercise between shift work groups. To compare PSQI and HEI-2015 characteristics between shift work groups, an independent t-test was used. When comparing the three-factor PSQI between shift work groups, a linear regression model was used. Multiple linear regression analysis was performed to investigate the association between shift work status and the three-factor PSQI after adjusting for confounding factors. The level of significance was set at $\mathrm{p}<0.05$.

\section{RESULTS}

General characteristics of participants $(n=298)$ are presented in Table 1. A total of 107 (35.9\%) participants were shift nurses and 191 (64.1\%) were non-shift nurses. The average age of participants was $29.9 \pm 6.9$ years. Their average BMI was $24.2 \pm 3.4$ $\mathrm{kg} / \mathrm{m}^{2}$. BMI was significantly $(\mathrm{p}<0.05)$ higher for shift nurses than for non-shift nurses. It was found that $7.5 \%$ of males and $92.5 \%$ of females were shift nurses. There was no statistically significant difference in sex, marital status, children having, smoking, alcohol use between shift and non-shift nurses (all $\mathrm{p}>0.05$ ). However, there was a significant $(\mathrm{p}<0.05)$ difference in working years between shift and non-shift nurses.

Associations between the three-factor PSQI model and the total PSQI score according to shift work status of participants are given in Table 2. Based on the three-factor PSQI model, scores for factor 1 (sleep efficiency), factor 2 (sleep quality) and factor 3 (daily disturbances) were significantly higher (poorer sleep quality) shift nurses than non-shift nurses ( $\mathrm{p}<0.05, \mathrm{p}<0.001$, and $\mathrm{p}<0.001$, respectively). Shift nurses also had higher PSQI scores (poorer sleep quality) than non-shift nurses ( $<<0.001$ ).

Energy, nutrient intakes, and HEI-2015 diet quality according to sleep quality and shift work status of participants are showed in Table 3. There was no statistically significant difference in energy or macronutrient intake according to sleep quality ( $\mathrm{p}>$ 0.05 ). Total diet quality was not significantly different between poor and good sleep quality groups $(\mathrm{p}>0.05)$. Among those with good sleep quality, total diet quality score was found to be sig- nificantly lower in shift nurses than in non-shift nurses ( $45.7 \pm$ 9.6 vs. $52.8 \pm 13.0, \mathrm{p}<0.05)$. Among those with poor sleep quality, there was no significant difference in total diet quality score between shift and non-shift nurses ( $p>0.05)$. For those with good sleep quality, scores of total protein intake, whole grain, seafood and vegetable proteins, and refined grains of non-shift nurses were significantly lower than those of shift nurses (all p <

Table 1. Comparison of the participants according to general characteristics and shift work status

\begin{tabular}{|c|c|c|c|c|}
\hline \multirow[b]{2}{*}{ Characteristics } & \multirow[b]{2}{*}{$\begin{array}{c}\text { Total } \\
(\mathrm{n}=298)\end{array}$} & \multicolumn{2}{|c|}{ Shift work status } & \multirow[b]{2}{*}{$\mathrm{p}$-value } \\
\hline & & $\begin{array}{c}\text { Shift } \\
\text { work } \\
(\mathrm{n}=107)\end{array}$ & $\begin{array}{c}\text { Non-shift } \\
\text { work } \\
(\mathrm{n}=191)\end{array}$ & \\
\hline Age (year) & $29.9 \pm 6.9$ & $29.7 \pm 6.5$ & $30.0 \pm 7.2$ & 0.745 \\
\hline $\begin{array}{l}\text { Body mass index } \\
\left(\mathrm{kg} / \mathrm{m}^{2}\right)\end{array}$ & $24.2 \pm 3.4$ & $24.9 \pm 3.7$ & $23.8 \pm 3.1$ & $0.005^{*}$ \\
\hline $\begin{array}{l}\text { Underweight } \\
\left(<18.5 \mathrm{~kg} / \mathrm{m}^{2}\right)\end{array}$ & $9(3.0)$ & $5(4.7)$ & $4(2.1)$ & 0.122 \\
\hline $\begin{array}{l}\text { Normal } \\
\left(18.5-24.9 \mathrm{~kg} / \mathrm{m}^{2}\right)\end{array}$ & $167(56.0)$ & $53(49.5)$ & $114(68.3)$ & \\
\hline $\begin{array}{l}\text { Overweight } \\
\left(25.0-29.9 \mathrm{~kg} / \mathrm{m}^{2}\right)\end{array}$ & $106(35.6)$ & $40(37.4)$ & $66(62.3)$ & \\
\hline Obese $\left(\geq 30 \mathrm{~kg} / \mathrm{m}^{2}\right)$ & $16(5.4)$ & $9(8.4)$ & $7(43.8)$ & \\
\hline Sex & & & & 0.566 \\
\hline Female & $276(92.6)$ & $99(92.5)$ & $177(92.7)$ & \\
\hline Male & $22(7.4)$ & $8(7.5)$ & $14(7.3)$ & \\
\hline Marital status & & & & 0.051 \\
\hline Single & $165(55.4)$ & $52(48.6)$ & $113(59.2)$ & \\
\hline Married & $133(44.6)$ & $55(51.4)$ & $78(40.8)$ & \\
\hline Having children & & & & 0.269 \\
\hline Yes & $117(39.3)$ & $45(42.1)$ & $72(37.7)$ & \\
\hline No & $181(60.7)$ & $62(57.9)$ & $119(62.3)$ & \\
\hline Working year & & & & $0.049^{*}$ \\
\hline $0-5$ & $171(57.4)$ & $53(49.5)$ & $118(61.8)$ & \\
\hline $6-10$ & $86(28.9)$ & $40(37.4)$ & $46(24.1)$ & \\
\hline$\geq 11$ & $41(13.8)$ & $14(13.1)$ & $27(14.1)$ & \\
\hline Smoking & & & & 0.368 \\
\hline Yes & $134(45.0)$ & $84(44.0)$ & $50(46.7)$ & \\
\hline No & $164(55.0)$ & $107(56.0)$ & $57(53.3)$ & \\
\hline Alcohol use & & & & 0.404 \\
\hline Yes & $55(18.5)$ & $21(19.6)$ & $34(17.8)$ & \\
\hline No & $243(81.5)$ & $86(80.4)$ & $157(82.2)$ & \\
\hline Regular exercise & & & & $0.014^{*}$ \\
\hline Yes & $70(23.5)$ & $17(15.9)$ & $53(27.7)$ & \\
\hline No & $228(76.5)$ & $90(84.1)$ & $138(72.3)$ & \\
\hline
\end{tabular}

All data are presented as $\mathrm{n}(\%)$ or mean \pm standard deviation values (independent sample t-test).

$* \mathrm{p}<0.05$. 
Table 2. Associations between shift work status and individual factors of PSQI (three-factor model)

\begin{tabular}{|c|c|c|c|c|}
\hline \multirow[b]{2}{*}{ PSQI } & \multirow[b]{2}{*}{ Total } & \multicolumn{2}{|c|}{ Shift work status } & \multirow[b]{2}{*}{ p-value } \\
\hline & & $\begin{array}{c}\text { Shift } \\
\text { work } \\
(\mathrm{n}=107)\end{array}$ & $\begin{array}{c}\text { Non-shift } \\
\text { work } \\
(\mathrm{n}=191)\end{array}$ & \\
\hline $\begin{array}{l}\text { Factor 1: sleep } \\
\text { efficiency }\end{array}$ & $1.9 \pm 1.6$ & $2.2 \pm 1.7$ & $1.7 \pm 1.5$ & $0.021^{*}$ \\
\hline Sleep duration & $1.2 \pm 0.8$ & $1.2 \pm 0.9$ & $1.1 \pm 0.8$ & 0.280 \\
\hline $\begin{array}{l}\text { Habitual sleep } \\
\text { efficacy }\end{array}$ & $0.7 \pm 0.9$ & $0.9 \pm 0.8$ & $0.6 \pm 0.8$ & $0.002^{*}$ \\
\hline Factor 2: sleep quality & $2.9 \pm 1.6$ & $3.4 \pm 1.7$ & $2.7 \pm 1.6$ & $<0.001^{* *}$ \\
\hline $\begin{array}{l}\text { Subjective sleep } \\
\text { quality }\end{array}$ & $1.2 \pm 0.6$ & $1.5 \pm 0.7$ & $1.1 \pm 0.6$ & $<0.001^{* *}$ \\
\hline Sleep latency & $1.5 \pm 1.1$ & $1.6 \pm 1.0$ & $1.4 \pm 1.1$ & 0.183 \\
\hline Sleeping pills & $0.2 \pm 0.6$ & $0.3 \pm 0.7$ & $0.2 \pm 0.5$ & 0.119 \\
\hline $\begin{array}{l}\text { Factor 3: daily } \\
\text { disturbances }\end{array}$ & $2.3 \pm 1.2$ & $2.6 \pm 1.2$ & $2.0 \pm 1.1$ & $<0.001^{* *}$ \\
\hline Sleep disturbance & $1.3 \pm 0.5$ & $1.4 \pm 0.5$ & $1.2 \pm 0.5$ & $0.026^{*}$ \\
\hline $\begin{array}{c}\text { Daytime sleep } \\
\text { dysfunction }\end{array}$ & $1.0 \pm 0.9$ & $1.3 \pm 1.0$ & $0.8 \pm 0.8$ & $<0.001^{* *}$ \\
\hline Total score of PSQI & $7.2 \pm 3.5$ & $8.2 \pm 3.6$ & $6.5 \pm 3.2$ & $<0.001^{* *}$ \\
\hline
\end{tabular}

Data are presented as mean \pm standard deviation values (independent sample t-test).

${ }^{*} \mathrm{p}<0.05 .{ }^{* *} \mathrm{p}<0.001$.

PSQI: Pittsburgh Sleep Quality Index.

0.05). For those with poor sleep quality, scores for dark green vegetables, legumes, and total protein of shift nurses were significantly lower than those of non-shift nurses $(\mathrm{p}<0.05)$.

Associations of shift work status with three PSQI factors were analyzed by multivariate linear regression models. Results are shown in Table 4. Multivariate linear regression analyses demonstrated that shift work status had significant effects sleep efficiency, sleep quality, and daily disturbances. The mean sleep efficiency score was significantly higher for shift nurses than for non-shift nurses $[\beta=0.141 \pm 0.017 ; 95 \%$ confidence interval (CI): $0.008-0.074 ; \mathrm{p}<0.05]$. Shift nurses working in shifts had significantly higher sleep quality score than non-shift nurses $(\beta=$ $0.055 \pm 0.016$; $95 \%$ CI: 0.023-0.087; $p<0.001)$. There was a significant interaction between daily disturbance and shift work status ( $\mathrm{p}=0.001$ ). The risk of daily disturbances in shift nurses was $22.7 \%$ higher. Results of multiple-adjusted models were similar to results of linear models. After adjustments, the mean sleep efficiency score for shift nurses was significantly lower than that for non-shift nurses in all models except for model 3 ( $\mathrm{p}<0.05$ ). In all models, the mean sleep quality score and mean daily disturbances score were significantly lower for shift nurses than for non-shift nurses (both $\mathrm{p}<0.01$ ).

\section{DISCUSSION}

This cross-sectional study revealed that shift work status was a factor affecting the sleep quality of nurses. According to the three-factor PSQI scoring model, shift work was significantly associated with all three factors (sleep efficiency, sleep quality, and daily disturbances) of PSQI. While the working style of individuals with poor sleep quality did not affect their diet quality, the diet quality of shift nurses among individuals with good sleep quality was worse than that of non-shift nurses with good sleep quality.

In this study, the average BMI of shift nurses was higher than that of non-shift nurses. Previous studies have reported that shift workers tend to be obese [20,21]. Since nurses work longer than regular work hours, suffer work stress, and have unhealthy dietary patterns with exposures to hospital infections, they are prone to obesity [22]. Shift work pattern is also one of factors contributing to weight gains in nurses as it leads to lifestyle changes related to nutrition and exercise. In addtion, it disrupts the circadian rhythm [23]. In this study, the proprotion of those who would exercise regularly was found to be lower among shift nurses than in non-shift nurses. Daily energy intake of shift nurses was also higher, although the difference was not statistically significant. These results may explain why the average BMI of shift nurses was higher.

The present study found that scores for sleep efficiency, sleep quality, and daily disturbances were higher for shift nurses than for non-shift nurses, similar to results of a previous study reporting that shift workers had higher sleep quality scores [24]. However, sleep quality and daily disturbance factor scores of shift nurses have been reported to be $4.41 \pm 2.61$ and $3.04 \pm 1.15$, respectively [24], higher than those found in current study. Moreover, many studies have found that daytime dysfunction and sleep latency of shift workers are affected by the manner of working $[25,26]$ Consistent with the literature, we observed that shift nurses experienced more daytime dysfunction. However, sleep latency was not affected by the shift work status in the present study. Softer light with a quiet and unhurried environment in the night is needed for an individual's good sleep. Therefore, sleep quality can decrease when the circadian arrangement is not achieved for shift workers [27]. The deterioration of sleep quality of shift nurses may be a sign of their inability to adapt to the circadian system.

Previous studies have reported that poor diet quality is associated with increased energy intake which may cause body weight gain due to secretion of appetite-stimulating hormone ghrelin $[28,29]$. This study found no significant difference in energy, nutrients intake, or diet quality according to sleep quality. Similarly, Kang et al. [30] have reported that there is no significant relationship between macronutrient intake and sleep quality. Contrary to our study, Katagiri et al. [31] have shown that those 
Table 3. Energy, nutrient intakes, and diet quality (HEl-2015) according to sleep quality and shift work status

\begin{tabular}{|c|c|c|c|c|c|c|c|c|c|}
\hline \multirow[b]{2}{*}{ Characteristics } & \multicolumn{4}{|c|}{ Good sleep quality $(\mathrm{n}=114)$} & \multicolumn{4}{|c|}{ Poor sleep quality $(\mathrm{n}=184)$} & \multirow[b]{2}{*}{$\mathrm{p}$-value } \\
\hline & Total & $\begin{array}{l}\text { Shift work } \\
(\mathrm{n}=25)\end{array}$ & $\begin{array}{l}\text { Non-shift work } \\
\quad(\mathrm{n}=89)\end{array}$ & $\begin{array}{c}\mathrm{p}- \\
\text { value }\end{array}$ & Total & $\begin{array}{l}\text { Shift work } \\
(\mathrm{n}=82)\end{array}$ & $\begin{array}{l}\text { Non-shift work } \\
\quad(\mathrm{n}=102)\end{array}$ & $\begin{array}{c}\mathrm{p}- \\
\text { value }\end{array}$ & \\
\hline \multicolumn{10}{|l|}{ Energy and nutrients } \\
\hline Energy (kkal) & $1632.6 \pm 441.4$ & $1727.0 \pm 411.7$ & $1606.1 \pm 448.0$ & 0.227 & $1581.7 \pm 482.4$ & $1599.1 \pm 459.1$ & $11567.7 \pm 502.2$ & 0.662 & 0.361 \\
\hline Carbohydrate (g) & $185.8 \pm 63.6$ & $186.8 \pm 65.8$ & $185.5 \pm 63.3$ & 0.933 & $184.3 \pm 65.2$ & $191.6 \pm 63.3$ & $178.5 \pm 66.5$ & 0.177 & 0.849 \\
\hline Protein $(\mathrm{g})$ & $71.8 \pm 27.3$ & $69.3 \pm 28.0$ & $80.7 \pm 23.0$ & 0.066 & $69.2 \pm 28.6$ & $68.9 \pm 29.3$ & $69.3 \pm 28.1$ & 0.934 & 0.422 \\
\hline Fat (g) & $64.1 \pm 22.8$ & $71.0 \pm 21.4$ & $62.2 \pm 22.8$ & 0.087 & $61.4 \pm 23.2$ & $59.9 \pm 21.8$ & $62.5 \pm 24.4$ & 0.467 & 0.322 \\
\hline Fiber (g) & $16.6 \pm 11.3$ & $18.9 \pm 11.7$ & $15.9 \pm 11.1$ & 0.261 & $15.3 \pm 11.9$ & $16.1 \pm 12.3$ & $14.7 \pm 11.7$ & 0.430 & 0.363 \\
\hline \multicolumn{10}{|l|}{ HEI-2015 } \\
\hline Total fruits & $1.8 \pm 1.6$ & $2.1 \pm 1.8$ & $1.8 \pm 2.0$ & 0.417 & $1.8 \pm 1.9$ & $1.8 \pm 1.9$ & $1.8 \pm 1.9$ & 0.906 & 0.978 \\
\hline Whole fruit & $1.9 \pm 2.0$ & $2.2 \pm 1.8$ & $1.9 \pm 2.1$ & 0.463 & $2.0 \pm 2.0$ & $2.1 \pm 2.1$ & $1.9 \pm 2.0$ & 0.650 & 0.816 \\
\hline Total vegetables & $2.2 \pm 1.5$ & $2.1 \pm 1.6$ & $2.2 \pm 1.5$ & 0.974 & $2.2 \pm 1.5$ & $2.0 \pm 1.4$ & $2.2 \pm 1.5$ & 0.297 & 0.967 \\
\hline Greens and beans & $2.5 \pm 2.1$ & $2.9 \pm 2.3$ & $2.4 \pm 2.1$ & 0.332 & $2.7 \pm 2.1$ & $2.3 \pm 2.1$ & $3.0 \pm 2.0$ & $0.012^{*}$ & 0.517 \\
\hline Whole grains & $1.7 \pm 2.7$ & $3.0 \pm 3.5$ & $1.3 \pm 2.3$ & $0.027^{*}$ & $1.7 \pm 2.0$ & $1.3 \pm 2.3$ & $1.1 \pm 1.8$ & 0.541 & 0.098 \\
\hline Dairy products & $3.3 \pm 2.8$ & $2.9 \pm 2.9$ & $3.5 \pm 3.5$ & 0.418 & $2.9 \pm 2.6$ & $2.8 \pm 2.5$ & $2.9 \pm 2.7$ & 0.803 & 0.129 \\
\hline Total protein & $4.3 \pm 1.2$ & $4.8 \pm 0.7$ & $4.1 \pm 1.3$ & $0.003^{*}$ & $4.2 \pm 1.2$ & $3.9 \pm 1.4$ & $4.4 \pm 1.2$ & $0.039 *$ & 0.352 \\
\hline $\begin{array}{l}\text { Seafood and } \\
\text { vegetable proteins }\end{array}$ & $2.2 \pm 2.2$ & $3.5 \pm 2.1$ & $1.8 \pm 2.1$ & $0.001^{*}$ & $1.9 \pm 2.1$ & $1.7 \pm 2.0$ & $2.1 \pm 2.2$ & 0.194 & 0.289 \\
\hline Fatty acids & $7.5 \pm 3.5$ & $7.3 \pm 3.8$ & $7.6 \pm 3.5$ & 0.733 & $7.3 \pm 3.6$ & $7.5 \pm 3.3$ & $7.1 \pm 3.7$ & 0.437 & 0.542 \\
\hline Refined grains & $3.0 \pm 3.7$ & $4.7 \pm 3.9$ & $2.5 \pm 3.5$ & $0.008^{*}$ & $2.7 \pm 3.5$ & $2.5 \pm 3.6$ & $2.8 \pm 3.6$ & 0.569 & 0.438 \\
\hline Sodium & $1.3 \pm 2.5$ & $2.0 \pm 2.9$ & $1.0 \pm 2.4$ & 0.082 & $1.8 \pm 3.0$ & $1.7 \pm 2.9$ & $1.9 \pm 3.1$ & 0.657 & 0.134 \\
\hline Saturated Fats & $10.0 \pm 0.0$ & $10.0 \pm 0.0$ & $10.0 \pm 0.0$ & - & $10.0 \pm 0.0$ & $10.0 \pm 0.0$ & $10.0 \pm 0.0$ & 0.437 & - \\
\hline Added sugars & $5.2 \pm 4.7$ & $4.8 \pm 4.6$ & $5.4 \pm 4.7$ & 0.589 & $6.0 \pm 4.6$ & $5.9 \pm 4.7$ & $6.1 \pm 4.9$ & 0.641 & 0.157 \\
\hline Total diet quality & $47.2 \pm 10.8$ & $45.7 \pm 9.6$ & $52.8 \pm 13.0$ & $0.003^{*}$ & $46.7 \pm 10.5$ & $45.6 \pm 9.9$ & $47.6 \pm 10.9$ & 0.206 & 0.687 \\
\hline
\end{tabular}

Data are presented as mean \pm standard deviation values (independent sample t-test).

${ }^{*} \mathrm{p}<0.05$.

HEI-2015: Healthy Eating Index-2015.

with poor sleep quality consume more carbohydrates and energy. However, many studies have found a significant relationship between poor sleep quality and low energy intake [32,33]. On the other hand, Zuraikat et al. [34] have shown that those with poor sleep quality have a high intake of added sugar and a lower intake of whole grain and unsaturated fatty acid. Although sleep quality affects eating behavior by many mechanisms (sensitivity to food reward, change in appetite hormones, hedonic eating desire, etc.), results of the present study were different from those of Chaput [29].

In this study, daily intakes of energy were similar for shift and non-shift nurses. Besides, macronutrient and fiber intakes were not affected by the shift work status. Although working in shifts negatively affected sleep quality, it did not affect the dietary quality. Beebe et al. [25] have reported that shift work pattern does not affect sleep or dietary quality. However, they indicated that an improvement could be achieved in the intake of whole grain, fat, and sodium for general eating habits of nurses [25]. Another study has revealed that energy intake of shift workers is higher than daytime workers, although their diet quality are similar [35]. It has been reported that even if the diet quality does not alter, increased energy intake may lead to adverse health outcomes for night shift workers [35]. Different from results of this study, the literature has reported that nurses working in shifts receive more energy, protein, fat, and fiber than others [36]. Depending on the shift work status, different literature results of energy and nutrient intakes might be associated with the season in which records are kept. Another study has found that those who work in night shifts have higher intakes of energy, carbohydrate, total fat, and saturated fat but lower intakes of protein during the winter months, although their intakes of nutrients during summer months are similar to those of daytime workers [37]. We collected our research data during winter months. Our results are similar to results of the study conducted by van de Langenber et al. [37] in the summer. This striking similarity might be explained by the fact that participants included in the study had different ages and cultures.

The effect of shift work status on sleep quality factors was eval- 
Helvaci G, et al.

Table 4. Multivariate linear regression analysis of associations between shift-work and individual factors of Pittsburgh Sleep Quality Index (three-factor model)

\begin{tabular}{|c|c|c|c|c|c|c|}
\hline \multirow{2}{*}{$\begin{array}{c}\text { Independent } \\
\text { variable }\end{array}$} & \multirow{2}{*}{$\begin{array}{l}\text { Dependent } \\
\text { variable }\end{array}$} & \multicolumn{2}{|c|}{ Unstandardized coefficient } & \multicolumn{2}{|c|}{ Standardized coefficient } & \multirow{2}{*}{$\mathrm{p}$-value } \\
\hline & & B & Standard error & $\beta$ & 95\% Confidence interval & \\
\hline \multicolumn{7}{|l|}{ Sleep efficiency } \\
\hline \multirow[t]{2}{*}{ Crude } & Shift-work & 0.041 & 0.017 & 0.140 & $0.008-0.074$ & $0.015^{*}$ \\
\hline & Non-shift work & (Reference) & & (Reference) & & \\
\hline \multirow[t]{2}{*}{ Model 1} & Shift-work & 0.041 & 0.017 & 0.140 & $0.008-0.073$ & $0.015^{*}$ \\
\hline & Non-shift work & (Reference) & & (Reference) & & \\
\hline \multirow[t]{2}{*}{ Model 2} & Shift-work & 0.038 & 0.017 & 0.129 & $0.005-0.071$ & $0.026^{*}$ \\
\hline & Non-shift work & (Reference) & & (Reference) & & \\
\hline \multirow[t]{2}{*}{ Model 3} & Shift-work & 0.034 & 0.017 & 0.116 & $0.001-0.068$ & 0.050 \\
\hline & Non-shift work & (Reference) & & (Reference) & & \\
\hline \multicolumn{7}{|l|}{ Sleep quality } \\
\hline \multirow[t]{2}{*}{ Crude } & Shift-work & 0.055 & 0.016 & 0.192 & $0.023-0.087$ & $<0.001^{* *}$ \\
\hline & Non-shift work & (Reference) & & (Reference) & & \\
\hline \multirow[t]{2}{*}{ Model 1} & Shift-work & 0.054 & 0.016 & 0.190 & $0.023-0.086$ & $<0.001^{* *}$ \\
\hline & Non-shift work & (Reference) & & (Reference) & & \\
\hline \multirow[t]{2}{*}{ Model 2} & Shift-work & 0.054 & 0.016 & 0.190 & $0.023-0.086$ & $<0.001^{* *}$ \\
\hline & Non-shift work & (Reference) & & (Reference) & & \\
\hline \multirow[t]{2}{*}{ Model 3} & Shift-work & 0.051 & 0.016 & 0.179 & $0.019-0.083$ & $0.002^{*}$ \\
\hline & Non-shift work & (Reference) & & (Reference) & & \\
\hline \multicolumn{7}{|l|}{ Daily disturbances } \\
\hline \multirow[t]{2}{*}{ Crude } & Shift-work & 0.086 & 0.022 & 0.227 & $0.044-0.129$ & $<0.001^{* *}$ \\
\hline & Non-shift work & (Reference) & & (Reference) & & \\
\hline \multirow[t]{2}{*}{ Model 1} & Shift-work & 0.083 & 0.021 & 0.218 & $0.041-0.125$ & $<0.001^{* *}$ \\
\hline & Non-shift work & (Reference) & & (Reference) & & \\
\hline \multirow[t]{2}{*}{ Model 2} & Shift-work & 0.082 & 0.022 & 0.216 & $0.040-0.125$ & $<0.001^{* *}$ \\
\hline & Non-shift work & (Reference) & & (Reference) & & \\
\hline \multirow[t]{2}{*}{ Model 3} & Shift-work & 0.079 & 0.022 & 0.207 & $0.036-0.122$ & $<0.001^{* *}$ \\
\hline & Non-shift work & (Reference) & & (Reference) & & \\
\hline
\end{tabular}

Crude: work type (non-shift work $=0$, shift-work $=1$ ). Model 1: adjusted for sex (female $=0$, male $=1$ ), age (continous, year), and body mass index (continous $\mathrm{kg} / \mathrm{m}^{2}$ ). Model 2: adjusted for model $1+$ marital status (yes $=0$, no $=1$ ), having children (yes $=0$, no $=1$ ), and working years $(0-5$ years $=0,6-10$ years $=1, \geq 11$ years $=2)$. Model 3: adjusted for model $1+$ model $2+$ smoking status, alcohol consumption, and regular exercise.

${ }^{*} \mathrm{p}<0.05 .{ }^{* *} \mathrm{p}<0.001$.

uated by multiple linear regression analysis. Consistent with the literature [24], it was found that sleep efficiency, sleep quality, and daily disturbance scores were statistically significantly higher for shift nurses than for non-shift nurses. Similar results obtained after adjusting for confounding variables. Several studies have reported that advanced age, under 24 years of age, gastrointestinal symptoms, and high-stress levels are risk factors that might contribute to poor sleep quality $[38,39]$. In this study, in the model in which all variables were adjusted, relationships of shift work status with sleep quality and daily disturbance were weaker than those with a crude model. There might other confounding factors affecting our results.

\section{Study Limitations and Strength}

In terms of limitations of this study, as it was a cross-sectional study, results might not be generalizable for all nurses. This study was conducted on nurses working at two hospitals in Ankara. This might lead to a potential bias for our results. Another limitation of this study was the lack of polysomnographic tests to determine physiological changes and precise parameters during sleep. Our results were based on participants' self-reports. Dietary data with the 24-hour recall method might cause over reporting or under reporting. Moreover, only $24 \mathrm{HR}$ was unable to account for day-to-day variation. Two or more non-consecutive recalls could better estimate usual dietary intake distribu- 
tions. Nurses working in shifts consisted of those who were rotating work or only at night. Real differences between shift work patterns might not have been revealed. In addition, we know little about influencing factors such as emotional health and chronic fatigue. Multicenter studies are needed to verify results of the present study and identify differences according to different shift-work schedules. Despite these limitations, the application of the three-factor model in the analysis of sleep quality provided more accurate results than PSQI in determining the severity and type of sleep disorders in nurses. Therefore, it provides data to guide us for choosing the appropriate sleep quality method.

\section{Conclusion}

In conclusion, shift work was found to have a significant association with sleep quality. Futhermore, among individuals with good sleep quality, the diet quality of shift nurses was worse than that of non-shift nurses. Since the present study revealed negative effects of the shift work system on the health of nurses, it can help health care providers resolve existing problems. Measures can be taken in a way to extend the time between shift work cycles in order to improve their sleep quality such as allowing nurses to sleep for short periods during their night shift or shortening their working hours in the shift. Dietary and sleep quality are important for nurses to improve their overall health and provide standard patient care during their job performance. Therefore, nutrition education to be given to nurses should be focused on limiting the intake of excesse energy, saturated fat, trans fat, sugar, and cholesterol, but increasing the consumption of foods such as fruits, vegetables, whole grain, and lean meat. It should be aimed to facilitate their access to healthy foods such as selling healthy foods in the hospital canteen and providing them opportunities for physical activities. Health and nutritional status of nurses should be pursued periodically and necessary precautions should be taken. Further studies are needed on the adaptation of dietary habits of healthcare professionals working in shifts to their working hours.

\section{Acknowledgments}

We are grateful to nurses for participating in this study.

\section{Conflicts of Interest}

The authors have no financial conflicts of interest.

\section{Authors' Contribution}

Conceptualization: Helvaci G, Yardimci H. Data curation: Aslan Çin NN. Formal analysis: Aslan Çin NN. Investigation: Helvaci G, Canbulat Ş. Methodology: Helvaci G, Aslan Çin NN. Project administration: Helvaci G, Canbulat Ş, Yardimci H. Resources: all authors. Software: Aslan Çin NN. Supervision: Helvaci G, Yardimci H. Validation: Helvaci G, Aslan Çin NN, Yardimci H. Writing-original draft: Helvaci G, Yardimci H. Writing—review \& editing: Helvaci G, Aslan Çin NN.

\section{REFERENCES}

1. Pepłońska B, Nowak P, Trafalska E. The association between night shift work and nutrition patterns among nurses: a literature review. $\mathrm{Med} \mathrm{Pr}$ 2019;70:363-76.

2. Kim MS, Kim JR, Park KS, Kang YS, Choe MSP. Associations between sleep quality, daytime sleepiness, with perceived errors during nursing work among hospital nurses. J Agric Med Community Health 2013;38: 229-42.

3. Sun Q, Ji X, Zhou W, Liu J. Sleep problems in shift nurses: a brief review and recommendations at both individual and institutional levels. J Nurs Manag 2019;27:10-8.

4. Westerterp-Plantenga MS. Sleep, circadian rhythm and body weight: parallel developments. Proc Nutr Soc 2016;75:431-9.

5. Guerrero-Vargas NN, Espitia-Bautista E, Buijs RM, Escobar C. Shiftwork: is time of eating determining metabolic health? Evidence from animal models. Proc Nutr Soc 2018;77:199-215.

6. Knutsson A. Health disorders of shift workers. Occup Med (Lond) 2003;53:103-8.

7. Horton Dias C, Dawson RM. Hospital and shift work influences on nurses' dietary behaviors: a qualitative study. Workplace Health Saf 2020;68:374-83.

8. Wong H, Wong MCS, Wong SY, Lee A. The association between shift duty and abnormal eating behavior among nurses working in a major hospital: a cross-sectional study. Int J Nurs Stud 2010;47:1021-7.

9. Cain SW, Filtness AJ, Phillips CL, Anderson C. Enhanced preference for high-fat foods following a simulated night shift. Scand J Work Environ Health 2015;41:288-93.

10. Tada Y, Kawano Y, Maeda I, Yoshizaki T, Sunami A, Yokoyama Y, et al. Association of body mass index with lifestyle and rotating shift work in Japanese female nurses. Obesity (Silver Spring) 2014;22:2489-93.

11. Park E, Lee HY, Park CSY. Association between sleep quality and nurse productivity among Korean clinical nurses. J Nurs Manag 2018;26: 1051-8.

12. World Health Organization. Obesity: preventing and managing the global epidemic: report of a WHO consultation. Singapore: World Health Organization 2000.

13. Buysse DJ, Reynolds CF 3rd, Monk TH, Berman SR, Kupfer DJ. The Pittsburgh Sleep Quality Index: a new instrument for psychiatric practice and research. Psychiatry Res 1989;28:193-213.

14. Ağargün MY, Kara H, Anlar O. Pittsburgh uyku kalitesi indeksinin geçerliği ve güvenirliği [Validity and reliability of Pittsburg Sleep Quality Index]. Turk Psikiyatri Derg 1996;7:107-15.

15. Cole JC, Motivala SJ, Buysse DJ, Oxman MN, Levin MJ, Irwin MR. Validation of a 3-factor scoring model for the Pittsburgh Sleep Quality Index in older adults. Sleep 2006;29:112-6.

16. Rakıcıoğlu N, Acar Tek N, Ayaz A, Pekcan G. Yemek ve Besin Fotoğraf Kataloğu [Photo catalog of foods and nutrients: measures and amounts]. Ankara: Hatipoğlu Yayınevi 2012.

17. Merdol Kutluay T. Toplu beslenme yapılan kurumlar için standart yemek tarifeleri [Standard meal recipes for institutions with collective nutrition]. Ankara: Hatipoğlu Yayınevi 2003.

18. BeBiS. BeBiS version 8.1 [software]. [cited 2020 Aug 16]. Available from: https://bebis.com.tr/.

19. Krebs-Smith SM, Pannucci TE, Subar AF, Kirkpatrick SI, Lerman JL, Tooze JA, et al. Update of the Healthy Eating Index: HEI-2015. J Acad Nutr Diet 2018;118:1591-602.

20. Karlsson B, Knutsson A, Lindahl B. Is there an association between shift work and having a metabolic syndrome? Results from a population based study of 27,485 people. Occup Environ Med 2001;58:747-52.

21. Zhao I, Bogossian F, Song S, Turner C. The association between shift work and unhealthy weight: a cross-sectional analysis from the Nurses and Midwives' e-Cohort Study. J Occup Environ Med 2011;53:153-8.

22. Aslam M, Siddiqui AA, Sandeep G, Madhu SV. High prevalence of obesity among nursing personnel working in tertiary care hospital. $\mathrm{Di}$ - 
abetes Metab Syndr 2018;12:313-6.

23. Eberly R, Feldman H. Obesity and shift work in the general population. Internet J Allied Health Sci Pract 2010;8:10.

24. Zhang L, Sun DM, Li CB, Tao MF. Influencing factors for sleep quality among shift-working nurses: a cross-sectional study in China using 3 -factor Pittsburgh Sleep Quality Index. Asian Nurs Res (Korean Soc Nurs Sci) 2016;10:277-82.

25. Beebe D, Chang JJ, Kress K, Mattfeldt-Beman M. Diet quality and sleep quality among day and night shift nurses. J Nurs Manag 2017;25:54957.

26. Huth JJ, Eliades A, Handwork C, Englehart JL, Messenger J. Shift worked, quality of sleep, and elevated body mass index in pediatric nurses. J Pediatr Nurs 2013;28:e64-73.

27. Wickwire EM, Geiger-Brown J, Scharf SM, Drake CL. Shift work and shift work sleep disorder: clinical and organizational perspectives. Chest 2017;151:1156-72.

28. Cheng FW, Li Y, Winkelman JW, Hu FB, Rimm EB, Gao X. Probable insomnia is associated with future total energy intake and diet quality in men. Am J Clin Nutr 2016;104:462-9.

29. Chaput JP. Sleep patterns, diet quality and energy balance. Physiol Behav 2014;134:86-91.

30. Kang B, Doo M, Kim Y. Associations between self-reported sleep quality and duration and dietary consumptions, psychological symptoms, and obesity in Korean adults. Prev Nutr Food Sci 2017;22:271-6.

31. Katagiri R, Asakura K, Kobayashi S, Suga H, Sasaki S. Low intake of vegetables, high intake of confectionary, and unhealthy eating habits are associated with poor sleep quality among middle-aged female Japanese workers. J Occup Health 2014;56:359-68.
32. Hashimoto A, Inoue H, Kuwano T. Low energy intake and dietary quality are associated with low objective sleep quality in young Japanese women. Nutr Res 2020;80:44-54.

33. Zadeh SS, Begum K. Comparison of nutrient intake by sleep status in selected adults in Mysore, India. Nutr Res Pract 2011;5:230-5.

34. Zuraikat FM, Makarem N, Liao M, St-Onge MP, Aggarwal B. Measures of poor sleep quality are associated with higher energy intake and poor diet quality in a diverse sample of women from the go red for women strategically focused research network. J Am Heart Assoc 2020;9:e014587.

35. Hulsegge G, Boer JM, van der Beek AJ, Verschuren WM, Sluijs I, Vermeulen R, et al. Shift workers have a similar diet quality but higher energy intake than day workers. Scand J Work Environ Health 2016;42:4 59-68.

36. Seychell J, Reeves S. The effect of shift work on the diet of accident and emergency nurses at a general hospital in Malta. Nutr Food Sci 2017; 47:165-74.

37. van de Langenberg D, Vlaanderen JJ, Dollé MET, Rookus MA, van Kerkhof LWM, Vermeulen RCH. Diet, physical activity, and daylight exposure patterns in night-shift workers and day workers. Ann Work Expo Health 2019;63:9-21.

38. Chan MF. Factors associated with perceived sleep quality of nurses working on rotating shifts. J Clin Nurs 2009;18:285-93.

39. Kageyama T, Nishikido N, Kobayashi T, Oga J, Kawashima M. Crosssectional survey on risk factors for insomnia in Japanese female hospital nurses working rapidly rotating shift systems. J Hum Ergol (Tokyo) 2001;30:149-54 